\title{
Spinoza e o Direito de Resistência ${ }^{1}$
}

\author{
Spinoza and the Right of Resistance
}

\section{Francisco de Guimaraens}

Pontifícia Universidade Católica do Rio de Janeiro (PUC-RIO), RJ, Brasil.

Maurício Rocha

Pontifícia Universidade Católica do Rio de Janeiro (PUC-RIO), RJ, Brasil.

\begin{abstract}
Resumo: Este trabalho tem o objetivo de analisar o conceito de direito de resistência formulado por Spinoza. Para atingir tal objetivo, desenvolve-se, de início, neste trabalho análise sobre as circunstâncias teóricas e históricas em meio às quais Spinoza construiu seu conceito de direito de resistência. Em seguida, realiza-se investigação sobre determinadas categorias do pensamento político-jurídico spinozano pertinentes ao conceito de direito de resistência, como as noções de direito natural, a relação entre obediência política e resistência e os modos de expressão política e institucional do direito de resistência propostos por Spinoza.
\end{abstract}

Palavras-chave: Spinoza. Direito de Resistência. Direito Natural.
Abstract: This work aims at the analysis of the Spinoza's concept of right of resistance. At the beginning of this work is developed an investigation about the historic and theoretical circumstances that influenced the Spinoza's reflections about the right of resistance. After this investigation, some spinozian political and juridical categories related to the right of resistance concept are analysed, such as: the idea of natural right, the relation between political obedience and resistance and the political and institutional mechanisms of right of resistance proposed by Spinoza.

Keywords: Spinoza. Right of Resistance. Natural Right.

1 Recebido em: 5/8/2014

Revisado em: 2/10/2014

Aprovado em: 9/10/2014 


\section{Introdução}

Direito de resistência: conceito em constante disputa no pensamento político que assinala o limite do poder político. A resistência se afirma onde o poder já não mais se sustenta nas condições necessárias de seu exercício. Mas seria o direito de resistência mera reatividade ao poder arbitrário, ilegítimo e intolerável?

Spinoza responde originalmente essa pergunta. O objetivo desse trabalho, portanto, é acompanhar os elementos conceituais do pensamento político spinozano, a fim de demonstrar que o direito de resistência assume outra configuração e outra função na perspectiva de Spinoza. Trata-se, portanto, de seguir a trilha deixada por Spinoza, que permite entender positivamente o conceito de direito de resistência, ou seja, o direito de resistência não é, para Spinoza, um movimento reativo, voltado contra a violação do pacto e orientado para a reconstituição do pacto rompido pelos governantes. Em Spinoza, o direito de resistência é o esforço concretizado de contínua instituição do poder político, ainda que essa contínua instituição signifique a própria reorganização institucional. Importa para Spinoza pensar a resistência, o porvir e a possibilidade de institucionalização da resistência, e não a resistência, o passado ou mesmo o voluntarismo resistente. Transformar a resistência em hábito estimulado e conservado pelas instituições políticas: eis a racionalidade democrática que opera no pensamento político de Spinoza.

Para alcançar o objetivo exposto, este trabalho se desenvolve em torno de quatro elementos: a) contextualização do debate sobre o direito de resistência no período em que Spinoza produziu seu pensamento político; b) análise do fundamento do direito de resistência na filosofia de Spinoza, a potência da multidão, cuja atualização contínua por intermédio de mecanismos institucionais constitui o verdadeiro enigma político; c) relação entre obediência política e resistência no pensamento de Spinoza, relação essa que permite Spinoza enfrentar de modo original duas questões: desobedecer é obedecer? É possível romper os pactos? d) Explicitação dos mecanismos de expressão do direito de resistência - a liberdade de expressão e o controle popular das armas - capazes de conservar a liberdade política sem a necessidade de ruptura do pacto, ou 
seja, uma expressão contínua e positiva do direito de resistência, e não eventual e reativa.

\section{Direito de Resistência}

Aquele que vos domina tanto só tem dois olhos, duas mãos, um só corpo e não tem senão o menor homem do grande e infinito número de nossas cidades, senão a vantagem que lhe dais para vos destruir. De onde ele tirou tantos olhos, com os quais vos espia, se vós não o cedestes? Como terá ele tantas mãos, para vos golpear, se não as toma de vós? Como ousaria atacar-vos, se não estivesse em conluio convosco? [...] Sede resolutos em não mais servir e ei-vos livres. Não quero que o empurreis ou abaleis, mas apenas que não o sustenteis mais e o vereis, qual grande colosso a quem se tirou a base, desfazer-se debaixo do próprio peso e romper-se. (LA BOÉTIE, 2003, p. 29-30)

Os bons exemplos nascem da boa educação; a boa educação, das boas leis; e as boas leis, dos tumultos que muitos condenam sem ponderar [...] os desejos dos povos livres raras vezes são perniciosos à liberdade, visto que nascem ou de serem oprimidos ou da suspeita de que virão a sê-lo. (MAQUIAVEL, 2007, p. 4)

"Se forem poucos a decidir tudo de acordo apenas com o seu afeto, perece a liberdade e o bem comum". (SPINOZA, 2009, p. 14)

A ideia de um direito de resistência formou-se em um processo que envolve determinações teológicas e políticas simultâneas e tem por marco uma série de eventos que atravessam a história européia: as guerras camponesas na Alemanha, a guerra de independência nacional das Províncias Unidas, o massacre de São Bartolomeu em Paris, a Revolução Inglesa. Dessas determinações deriva a figura inicial do problema do direito de resistência e sua inscrição em uma perspectiva conservadora, paradoxalmente conformista, por subordinar a resistência à ideia de restabelecimento da ordem preexistente. Essa figura comparece nos autores que formulam o direito de resistência antes de Spinoza - como também naqueles 
conhecidos como monarcômacos ${ }^{2}$. Em comum entre eles, o pressuposto de um duplo contrato da realeza, que assegura sua legitimidade na vontade de Deus e no compromisso de proteger e assegurar a vida dos súditos - em troca, estes lhe devem obediência.

Resistir ao poder régio é justo quando da ruptura deste contrato, e é um dever quando advém a forma tirânica - pecado diante de Deus e perjúrio diante dos homens. Nesse caso, defender uma insurreição contra o tirano, e mesmo conceder com sua eliminação física, não é contraditório com a defesa do poder monárquico e com a ordem estabelecida, ao contrário, é sua condição. É esse retorno necessário à origem pressuposta (do poder concedido por Deus, do poder contratado com os homens), que constitui a imaginação teológico-política da figura inicial do direito de resistência (BOVE, 1996, p. 280). E é esse o contexto que confere aos libelos do final do século XVI um tom marcado pelo desejo de vingança, mais do que pelo valor da justiça. Nesta época se forja o termo tiranicídio - e ainda que Etienne La Boétie não tenha pregado o assassinato do tirano, as ideias expostas no Discurso inspirarão os regicidas. De todo modo, o que é relevante no tiranicídio é que ele delineia a figura da ilegitimidade da tirania e contribui para reformular o sentido da autoridade civil ou política. (SKINNER, 1996, p. 571)

Será preciso aguardar por Althusius para que uma teoria da prática constitucional e do direito de resistência seja proposta em outros termos, propriamente constitucionais. Ele pensará a constituição orgânica do corpo social e do corpo político, com seu conceito de consociatio e compreenderá que a resistência deriva da dupla natureza da soberania que é em parte popular, mas que também abriga a disposição tirânica de dominação ilimitada. Daí a necessidade de constituir juridicamente o direito de resistência como elemento componente do exercício da soberania. Enfim, institucionalizá-lo, através de uma lógica de contra poderes que ponha a sociedade a salvo, e a preserve, do estado de guerra resultante da tirania. Antonio Negri assinalou como Spinoza "reivindicava essa experiência política alternativa" de Althusius (NEGRI, 1993, p. 157). De fato, em Spinoza o mesmo tema reaparece, no momento de pensar as construções

2 Para um estudo sobre os "monarcômacos": (CARVALHO, 2007) 
constitucionais, seja no Tratado Teológico-Politico, XVII: “[...] é altura de vermos até que ponto um Estado assim constituído podia moderar os ânimos e conter quer os governantes, quer os governados, de modo a que nem estes se tornassem rebeldes, nem aqueles tiranos [...]", seja no Tratado Político, I, 6: "[...] que os administradores do Estado não se transformem em dominadores". (BOVE, 1996, p. 281)

Contra o que o pensamento de seu tempo vê como uma contradição, Spinoza rasga o horizonte limitado do senso comum dominante ao pensar, conjuntamente, a liberdade dos cidadãos e a autoridade do Estado (BOVE, 1996, p. 300). Contra as soluções formuladas em termos de transcendência de um poder exterior e antagônico ao corpo social - com a forma Estado absolutista se afirmando contra a liberdade dos cidadãos - ele pensará o liame interno do processo constitutivo de um Estado cujo caráter absoluto é determinado pelo grau de liberdade dos seus cidadãos. A dupla tensão dos polos obediência-resistência é constitutiva e responde ao problema da liberdade pré-política da multidão que seria fonte de um estado de guerra latente - esse direito de guerra que é, paradoxalmente, a garantia da liberdade, da paz e da segurança. Pois, como lembra PierreFrançois Moreau (2009, p. 27-44):

Spinoza pensa sempre as relações interindividuais como lógica da luta, e a questão é saber como esta lógica não se torna lógica de guerra. Há tensões que fazem viver a cidade, o problema é compreender como não degeneram em guerra.

A originalidade spinozana embaralha as pistas clássicas do pensamento político ao formular de outra maneira o problema das relações sociais - daí a solidão teórica face ao pensamento hegemônico (BALIBAR, 1990, p. 93) -, por pensar ao mesmo tempo obediência e resistência: trata-se de compreender a lógica da obediência do ponto de vista de sua verdade efetiva, como liberdade ou prudência da natureza humana (SPINOZA, 2009, IV, 5), pois as mesmas forças que ameaçam a ordem civil sustentam a resistência à opressão - daí o sentido da fórmula spinozana não suportar ser governado e dominado por um igual. Afinal, a obediência produz súditos-sujeitos, enquanto a resistência produz cidadãos. Esse 
modo de pensar, que articula obediência e resistência, se abre ao tempo e possibilita pensar o porvir sob outra forma que não mais o da mistificação teológica da Lei, da ficção teórica do contrato, do formalismo da aparência do direito ou mesmo da utopia.

No campo do direito, essa inovação ainda carece de maior esclarecimento e penetração, na medida em que é tradicional ainda hoje a distinção radical entre obediência e resistência. Um dos autores que reproduz esta distinção é Norberto Bobbio, para quem “[...] toda a história do pensamento político pode ser distinguida conforme se tenha posto o acento [...] no dever da obediência, ou [...] no direito à resistência (ou à revolução)" (BOBBIO, 2004, p. 131). Essa posição do autor se projeta quando da análise do dissenso entre Hobbes e Spinoza. A diferença entre os dois autores, para Norberto Bobbio, residiria na concepção do fim a que se dirige o Estado. A filosofia política hobbesiana apontaria para a garantia da ordem e da segurança, enquanto a spinozana consideraria a liberdade no lugar da ordem e da segurança.

A distinção entre os dois filósofos seria efeito de dois pontos de vista distintos de que partem para pensar o Estado e o direito. Enquanto Hobbes falaria do ponto de vista dos governantes - ex parte principis Spinoza haveria construído um pensamento jurídico-político a partir da perspectiva dos cidadãos, dos governados, ou seja, ex parte populi. Tal diferença de perspectiva haveria forçado Hobbes a investir seus esforços na construção de uma teoria política de justificação da obediência política e da unidade do Estado, enquanto a teoria spinozana estaria voltada para a defesa da liberdade, ou seja, para a resistência.

O que os divide [Hobbes e Spinoza] é a diversa concepção do fim último do Estado, que para Hobbes é a paz e a ordem, para Spinoza a liberdade, diferença que por sua vez repousa sobre uma diferença mais profunda, que permite mais do que todas contrapor uma teoria à outra: refiro-me à diferença com respeito à perspectiva principal da qual todo escritor de coisas políticas se coloca para expor o próprio pensamento, e que permite contrapor os escritores que se colocam ex parte principis, isto é, da parte dos governantes para justificar o seu direito de comandar e o dever dos súditos de obede- 
cer, aos escritores que se colocam ex parte Populi, ou seja, da parte dos governados para defender o seu direito de não serem oprimidos e o dever dos governantes de emanarem leis justas. Para quem se coloca ex parte principis, o problema principal do Estado é o da unidade do poder, que pode inclusive agir em prejuízo da liberdade dos singulares; para quem se coloca ex parte Populi, o problema principal é o da liberdade dos singulares, que pode inclusive agir em prejuízo da unidade. (BOBBIO, 2003, p. 144)

Bobbio termina por afirmar uma distinção que não se enquadra perfeitamente na obra de Spinoza, visto que seu pensamento político não registra qualquer antítese entre a obediência e a resistência. Na verdade, a obediência política seria a antítese da servidão política, razão pela qual se percebe a necessidade de conceber a obediência a partir da resistência. A rigor, há obediência política quando a resistência encontra meios de institucionalização e se torna, assim, um hábito que impede a transformação do cidadão, que, ao resistir, obedece, no servo, que, ao não resistir, se submete. Bobbio não deixa de notar esse outro modo de pensar a relação entre resistência e obediência, embora tal percepção não seja, em sua obra, suficiente para revisão da antítese por ele assinalada entre ambas. Ao relatar diversas formas constitucionalizadas de exercício do direito de resistência (separação de poderes, princípio da legalidade, federalismo, descentralização política, direito de oposição e investidura popular dos governantes), o autor reconhece, ainda que implicitamente, que a resistência é fundamental à obediência política e que a distinção entre obediência e servidão se encontra justamente na existência ou na inexistência de canais institucionais que viabilizam a expressão continuada e a atualização permanente da resistência. (BOBBIO, 2004, p. 135-137)

A resistência, em Spinoza, é o que permite pensar e experimentar a própria materialidade do tempo, a produção da socialidade e da própria política em sua dimensão imaginativa, conflituosa, ambígua de significados - temporalidade que determina o ritmo da estratégia imanente às relações de força que cabe conhecer, pelo mesmo imperativo da prudência, no qual se enraíza a produção de liberdade pública (BOVE, 1996, p. 300). A recusa da ideia de pacto, a recusa ao individualismo e a crítica da teologia-política conduzem a indagar em que condições emerge e se formula 
o desejo de uma multidão que se torna livre. Essa posição do problema seria o cerne da política spinozana (ZOURABICHVILI, 2009, p. 70): a multidão define a soberania, precede-a de direito, em virtude da tensão natural dos indivíduos para a comunidade, que se expressa na recusa à solidão que dá consistência à multidão. Vida civil e natureza são relativos um ao outro e, justamente, supõem a ameaça constante de regressão. Daí Spinoza pensar com e contra Hobbes.

\section{Direito Natural e Potência da Multidão}

A reflexão sobre o pensamento político de Spinoza deve necessariamente levar em consideração a afirmação contida na Carta $L$ a Jarig Jelles, na qual se estabelece nítida distinção entre seu pensamento político e o de Hobbes. Segundo Spinoza, a diferença entre ele e Hobbes reside no fato de Spinoza conservar o direito natural no interior da ordem política civil. Trata-se de afirmação fundamental à compreensão do conceito de direito de resistência.

De saída é necessário lembrar que o direito natural, para Spinoza, não é uma faculdade humana ou tampouco a expressão de uma ordem cosmológica transcendente que serve de inspiração e modelo à constituição de ordens políticas (MATHERON, 2011, p. 88). Spinoza usa o vocabulário de seus contemporâneos, que definem o direito em termos de faculdade ou poder moral. Mas por excluir toda transcendência da ordem natural, ele assimila esse poder moral ou faculdade ao puro e simples poder físico: potência de produção de efeitos reais na natureza. Todos os modos naturais (humanos ou não) que podem afirmar livremente sua potência atual possuem o direito de fazer o que fazem, quando o fazem, pois sua potência é a sua liberdade, a qual não é determinada em função de um fim erigido como norma de comportamento.

A extensão do direito natural subjetivo é definida pela composição das leis da natureza do indivíduo com as outras leis da natureza. Trata-se de uma resultante da combinação das leis da sua natureza e das leis da natureza inteira. Essa composição produz maior ou menor variação da livre potência à medida que ela é entravada ou auxiliada por causas externas, 
pois a potência depende da relação do que ela produz segundo as leis de sua natureza com as outras leis da Natureza que entravam ou favorecem sua afirmação. $\mathrm{O}$ direito de cada um é sempre uma parte da potência de toda a natureza: aquela que lhe permite agir sobre todas as outras partes. Por isso, a medida do direito é também a da individualidade e sofre variações relacionadas aos encontros com potências superiores e inferiores, produzindo mais ou menos efeitos. O conflito, no estado de natureza, levaria a uma situação limite na qual as potências individuais seriam praticamente incompatíveis entre si, na qual a dependência seria total para cada uma delas, sem contribuir em nada para a sua independência, ameaçando as individualidades de destruição. Para Spinoza, o direito natural no estado de natureza permanece separado das condições que permitem sua realização e seria uma hipótese cuja validade só tem sentido abstrato (no sentido spinozano do vocábulo, como algo que é pensado separado de suas causas).

Se existe diferença entre a condição hipotética de indivíduos isolados e a construção política, que se pode representar como uma passagem do estado de natureza à sociedade civil, esta diferença não corresponde a nenhuma "saída" do mundo natural para entrar em um outro - nada tem a ver com uma passagem da animalidade à humanidade -, contrariamente ao que tem lugar em outros teóricos do direito natural. Os mesmos elementos se reencontram em uma parte e, na outra, redistribuídos de outro modo por uma causalidade imanente. Os ideólogos do contrato descrevem as paixões como típicas do estado de natureza e, uma vez, o Estado criado, eles as veem como obstáculos ou freios ao seu funcionamento. Spinoza identifica direito natural e direito passional, constatando que nada muda desse ponto de vista, uma vez constituída a soberania. As paixões não são vícios, mas parte essencial da natureza humana, e não há razão para desaparecerem após o pacto.

O direito de cada um se estende até onde se estende sua potência determinada. $\mathrm{O}$ direito (jus) exprime a realidade originária da potência (potentia). Ele não emana de, nem se funda sobre. A questão não é dar uma justificação do direito, mas formar uma ideia adequada de suas determinações, da maneira como ele opera. A fórmula de Spinoza significa, de início, que o direito do indivíduo inclui tudo o que ele é efetivamente 
capaz de fazer e de pensar em condições dadas. Spinoza não cessa de criticar a interpretação da lei natural como o efeito de uma vontade providencial que age sobre as coisas, em vista de fins. A exclusão do finalismo do horizonte ontológico tem por consequência a inexistência de outra lei natural além do conjunto de leis necessárias da Natureza, às quais os indivíduos humanos estão submetidos como qualquer outra coisa.

Daí decorre uma nova definição de lei natural. Spinoza admite que essa lei determina a extensão e o conteúdo do direito natural subjetivo (como Hobbes). Mas ele a identifica como as leis intrínsecas da natureza individual. $\mathrm{O}$ direito natural subjetivo e o direito natural objetivo se confundem, visto que o indivíduo está submetido à lei natural (as paixões são tão naturais como os terremotos). Essas leis naturais se compõem com outras leis da natureza de modo que a extensão do direito natural subjetivo se reduz à composição das leis da natureza do indivíduo com as outras leis. Composição que produz maior ou menor variação da livre potência segundo a qual ela é entravada ou auxiliada por causas externas. A lei de natureza identifica obrigação e necessidade (pois esta rege as variações da potência). Ninguém é obrigado a buscar os meios legítimos de sua conservação, mas somente a fazer o que faz para perseverar no seu estado, por ser a isso determinado, seja lá o que fizer, nem mais, nem menos. Essa nova concepção de direito e de lei remaneja o conceito de "transferência de direito" e conduz a uma nova gênese do corpo político.

A instituição do corpo político é justamente o momento em que a presumida solidão dos indivíduos dá lugar à formação de um indivíduo superior, ou melhor, o momento em que a multidão age como um só indivíduo. A constituição da vida comum sob a forma de um poder político (imperium) ocorre para concretizar o direito natural de cada um e de todos, pois é o direito natural coletivo que se conserva na forma dessa associação. E desse ponto de vista, para Spinoza, o estado de multidão é sempre primeiro. Daí o problema de saber sob quais formas, e em qual medida, os direitos dos indivíduos se adicionarão, se multiplicarão, ou, ao contrário, se neutralizarão, e até mesmo se destruirão reciprocamente. É sobre essa base que se pode analisar a articulação dos direitos entre eles, na constituição de um sistema jurídico: como uma articulação de potências. São compatíveis direitos expressivos de potências que se adicio- 
nam ou se multiplicam; inversamente, são incompatíveis os que correspondem às potências que se destroem.

As consequências dessa equação direito/potência é que a igualdade dos direitos constitui um direito ou uma potência - que pode existir ou não segundo as circunstâncias, pois supõe condições: uma igualdade verdadeira entre certos homens ou entre todos os cidadãos de um Estado é resultante de instituições, de uma prática coletiva, que só tem chance de emergir se interessa a todos. As relações contratuais entre indivíduos (troca de bens, prestação de serviços) não são consequência de uma obrigação preexistente, mas a constituição de um direito, ou de uma potência nova. Só uma potência superior (um soberano) pode impedir a ruptura de contratos quando não existem mais interesses em concluí-los.

O direito do soberano nunca se estende para além de sua capacidade de se fazer obedecer. A sanção que ele exerce contra os delinquentes, criminosos ou rebeldes não exprime a necessidade de fazer respeitar um "interdito" superior, mas sua própria necessidade de conservação. Portanto, é como efeito das relações entre as potências, e não como um princípio constitutivo, que se pode colocar a equivalência do direito e do fato - enunciado que choca a moral. Seria um contrassenso interpretar essa concepção como uma variante da ideia de que o direito é a força. Mas se é a força que faz o direito, toda força superior à primeira sucede a seu direito. $\mathrm{E} o$ direito do mais forte nada acrescenta à força do mais forte, isto é, os poderes estabelecidos não são beneficiados de uma legitimidade irreversível.

Ao tratar das semelhanças e diferenças entre o pensamento político de Hobbes e o de Spinoza, Marilena Chauí apresenta com nitidez as noções de direito natural contra as quais Spinoza construiu a sua própria concepção:

Os dois filósofos definem o direito natural como um fato (da Natureza) e como um poder (de autoconservação), distanciando-se tanto da perspectiva jusnaturalista estóica (conhecida, mais tarde, como teoria do direito natural subjetivo), na qual o direito natural exprime a vontade racional de justiça, como da perspectiva cristã, na qual o direito natural subjetivo é acrescido da teoria do direito 
natural objetivo, entendido como existência de uma ordem jurídica natural decretada pela vontade de Deus sob a forma de leis divinas naturais, e anterior à ordem jurídica positiva, instituída pelos homens. (CHAUÍ, 2003, p. 291)

O direito natural é, portanto, uma modalidade singular de expressão da potência da natureza. Por essa razão, "[...] o direito natural de toda a natureza e, consequentemente, de cada indivíduo, estende-se até onde se estende a sua potência" (SPINOZA, 2009, II, 4). O direito natural é, neste sentido, a expressão política e social do conatus de cada indivíduo. Ou seja, o esforço em perseverar na existência (conatus) define aquilo que pode um certo indivíduo e é esta potência atual de perseverança que determina o alcance de seu direito. Falar em direito natural, portanto, significa duas coisas: 1) identificar aquilo que se pode efetivamente realizar, afinal toda potência em perseverar, para Spinoza, é efetiva e atual; 2) estabelecer estratégias e composições de potências que permitam melhorar as condições de perseverança na existência de tais potências e ampliar aquilo que efetiva e atualmente é possível realizar.

O direito natural, para Spinoza, não implica um dever-ser, mas um conjunto de práticas atuais determinadas pelo esforço em perseverar mediante as quais se constitui o horizonte da afirmação atual da potência constitutiva do direito natural. Deste modo, não há direito natural que não seja atual e que não se exerça, o que provoca uma fissura inconciliável entre Spinoza e a tradição jusnaturalista, razão pela qual é inadequado incluir Spinoza no campo do jusnaturalismo ${ }^{3}$.

\footnotetext{
3 Apesar de Spinoza muito claramente não fazer parte da tradição jusnaturalista, não é essa a opinião de certos autores que assim o qualificam. A título de exemplo, podem ser citados Miguel Reale, Simone Goyard-Fabre e Norberto Bobbio. Reale reúne determinados autores racionalistas, incluindo entre eles Descartes, Malenbranche, Spinoza e Leibniz, afirmando que o racionalismo é necessariamente jusnaturalista, pois todos afirmariam o dualismo entre direito natural e direito positivo, servindo o direito natural de fundamento para a moral e para o direito (REALE, 1998, p. 99). Já Goyard-Fabre realiza um interessante estudo sobre a distinção do conceito de conatus na filosofia política hobbesiana e na spinozana, inserindo os dois na tradição jusnaturalista (GOYARD-FABRE, 2002, p. 53-57). As duas abordagens parecem desatentas sobre o adequado conceito spinozano de direito natural, como se as palavras valessem mais do que os conceitos. Por último, a abordagem de Bobbio sobre a questão não se atém a
} 
A redefinição do conceito de direito natural realizada por Spinoza ainda carece de um elemento decisivo: se a política envolve dinâmicas coletivas, qual o sentido coletivo do direito natural? Spinoza apresenta a seguinte resposta à indagação: “[...] o direito do Estado, ou dos poderes soberanos, não é senão o próprio direito de natureza, o qual se determina pela potência, não já de cada um, mas da multidão, que é conduzida como que por uma só mente" (SPINOZA, 2009, III, 2). Ou seja, o conatus da multidão estabelece a medida do direito civil, do direito do Estado.

É preciso enfrentar a questão acima exposta. No pensamento político spinozano o direito natural não é mais uma faculdade abstrata subjetiva ou uma ordem objetiva transcendente, mas uma potência atual e imanente resultante da composição de potências singulares que formam uma nova singularidade, a multidão. A multidão, por sua vez, exprime uma potência da qual participam as singularidades constituintes e é condição necessária para perseverança das mesmas. A organização política para Spinoza envolve uma ação coletiva das potências singulares que se compõem a fim de instituir as condições necessárias à afirmação e à existência dos próprios direitos dos indivíduos constituintes da potência coletiva. Os homens, portanto, só possuem direitos na medida em que fundam direitos comuns, efeitos imediatos da potência da multidão. É o que se deduz da passagem abaixo:

O direito natural do homem, enquanto é determinado pela potência de cada um e é de cada um, é nulo e consiste mais numa opinião que numa realidade, porquanto não há nenhuma garantia de o manter. E o certo é que cada um pode tanto menos e, consequente-

determinados conceitos fundamentais da obra de Spinoza. Bobbio introduz Spinoza na tradição jusnaturalista e, ao argumentar, afirma que o bem, no pensamento spinozano, é tudo o que deriva da potência natural. Para demonstrar a tese, ele lembra do exemplo usado por Spinoza do peixe grande que, por ter potência para tanto, devora o peixe pequeno. O resultado da afirmação da potência natural do peixe grande seria bom e, por consequência, conforme ao direito natural. Trata-se de uma dedução do exemplo conferido por Spinoza precipitada, afinal, em inúmeros momentos de sua obra, Spinoza afirma categoricamente que, sob o ponto de vista da natureza, não existe bem ou mal. Para consulta à obra em que Bobbio inclui Spinoza na tradição jusnaturalista. (BOBBIO, 1997, p. 64-65) 
mente, tem tanto menos direito quanto mais razão tem para temer. A isto acresce que os homens, sem o auxílio mútuo, dificilmente podem sustentar a vida e cultivar a mente. E, assim, concluímos que o direito de natureza, que é próprio do gênero humano, dificilmente pode conceber-se a não ser onde os homens têm direitos comuns e podem, juntos, reivindicar para si terrar que possam habitar e cultivar, fortificar-se, repelir toda a força e viver segundo o parecer comum de todos eles. (SPINOZA, 2009, p. 15)

A partir do esclarecimento acima, torna-se mais fácil enfrentar a ideia de que o direito da cidade é determinado pela potência da multidão. As instituições políticas são, na verdade, efeito da potência constituinte da multidão e visam a promover as condições necessárias para a conservação da expressão atual de tal potência. O Estado, portanto, é resultado da instituição da potência coletiva da multidão, marcada por um processo de cooperação (auxílio mútuo) sem o qual não há qualquer direito comum a ser exercido. Além disso, sem uma potência comum às suas singularidades constituintes, os direitos dos indivíduos se esvaem por não encontrarem condições políticas e sociais necessárias para sua afirmação. Isso porque a potência dos indivíduos é ínfima frente à potência da natureza inteira, o que os força a entrar em relação de conveniência e de auxílio recíproco para ampliar aquilo que cada um pode realizar e, assim, se inscrever adequadamente na potência da natureza inteira. Duas conclusões decorrem dessas reflexões: 1) não há direitos individuais sem direitos comuns; 2) a instituição dos direitos comuns - expressão imediata da potência (direito natural) da multidão - demanda a constituição de um aparato institucional - o Estado - para conservação da potência da multidão. Eis a razão de ser da experiência política.

A partir do que se expôs, é possível tornar nítido o que Spinoza entende por "conservar o direito natural". Se a potência da multidão determina o direito do Estado, é o direito natural da multidão a medida do direito civil. Spinoza conserva o direito natural porque a potência da multidão, seu direito natural, é causa do direito do Estado ou, como dizem os juristas, do direito positivo. Inclusive, é sempre bom lembrar que, tendo em vista o sentido da causalidade na obra de Spinoza, trata-se de causa eficiente imanente, uma causa que não se afasta jamais de seus efeitos. 
Desse modo, a potência da multidão não entra em nenhuma hipótese em estado de latência após a instituição do Estado, mas permanece atual durante a perseverança na existência da multidão e de seu efeito político mais visível, o Estado. O direito de resistência, por sua vez, deve ser analisado a partir da noção de direito natural exposta por Spinoza, já devidamente esclarecida. É preciso, portanto, seguir em direção à análise do direito de resistência.

\section{Obediência Política e Resistência}

Se em toda sociedade se trata de obedecer, não poderíamos identificar o sujeito da obediência em uma livre República com o sujeito da obediência em uma tirania. O automatismo da obediência integral é um limite ideal, mas também contraditório, da obediência. (BOVE, 1996, p. 264)

A compreensão da relação entre o direito de resistência, a constituição da ordem política e a obediência política exige a análise da natureza resistente do conatus na filosofia de Spinoza. Laurent Bove entende que em dois momentos da Ética a natureza resistente do conatus se evidencia. (BOVE, 2010, p. 114)

Na Demonstração da Proposição 37 da Parte III e no Escólio da Proposição 45 da Parte IV, a resistência à tristeza caracteriza a expressão da potência de agir do homem. No primeiro exemplo, Spinoza afirma que "[...] tudo pelo qual se esforça o homem afetado de tristeza é por afastá-la" (SPINOZA, 2007, Parte III, Proposição 37, Demonstração). No segundo exemplo, o enunciado spinozano é o seguinte: "Por que, com efeito, seria melhor matar a fome e a sede do que expulsar a melancolia?" (SPINOZA, 2007, Parte IV, Proposição 45, Escólio 2). Nos dois casos, segundo Bove, Spinoza se vale de verbos que indicam uma ação de resistir, não apenas um padecimento resistente, conformado. Tristitia amovere e melancholiam expellere são os termos empregados nas passagens citadas. Ambas demonstram um movimento ativo e resistente do conatus que busca se afastar da tristeza e da melancolia, não apenas resistir a elas de 
maneira resignada. Há, portanto, já na concepção ética de Spinoza um reconhecimento de que a existência é permeada por resistências ativas das potências de agir que constituem as essências atuais das coisas ${ }^{4}$.

Esta natureza resistente constitui aspecto essencial do direito natural de cada indivíduo e da multidão. Se é próprio do conatus exprimir, ainda que em graus muito baixos, a potência de agir, o efeito político deste movimento resistente é a conservação do direito de resistência mesmo após a constituição do estado civil. $\mathrm{O}$ direito de resistência, que se exprime como direito natural, determina a medida do poder do Estado e estabelece o próprio sentido da obediência política. Trata-se de um direito de resistência ativo, e não meramente reativo, reparador. A multidão não é parte de um poder estatal transcendente, mas toma parte permanentemente no contínuo processo da instituição dos direitos comuns, razão de existência do Estado. É neste momento em que a ontologia e a política spinozanas se fundem. A multidão toma parte no processo de instituição dos direitos comuns, ou seja, de sua própria potência, no mesmo sentido em que as coisas atualmente existentes tomam parte no contínuo processo de afirmação do infinito atual. Sobre a questão ontológica da participação dos modos finitos no infinito, a passagem abaixo é esclarecedora:

Os modos, enquanto dotados de propriedades comuns ao todo e enquanto essências singulares dotadas de mesma força interna que a causa geradora, não são espécies de um gênero, nem individualidades substanciais, mas forças singulares (conatus), diferenciação infinitamente infinita da mesma substância. A natureza de cada modo singular, portanto, só pode ser compreendida por sua relação interna com o absoluto. Seu ser encontra-se nessa relação e é esta que o põe em movimento, fazendo-o passar do "ser parte" ao "tomar parte” na potência infinita a que pertence. (CHAUI, 1999, p. 49)

\footnotetext{
4 Como lembra Tatiana Roque: "Na palavra resistência há, antes de tudo, o prefixo re, que aponta para uma duplicação, uma insistência, um desdobramento, uma dobra, "outra vez". Do que o segue, lê-se um substantivo derivado do verbo sistere: parar, permanecer, ficar, ficar de pé, estar presente. A esse verbo se associa também a stantia da palavra resistência, que invoca a estadia, ideia perfeitamente expressa pela transitoriedade do verbo estar, uma das preciosas singularidades do português. Até aqui, portanto, resistir é insistir em estar - em permanecer, em ficar de pé’. (ROQUE, 2002, p. 23-32)
} 
Se tomar parte na potência infinita é uma ação contínua, no mesmo sentido deve ser compreendida a instituição e a afirmação da potência da multidão em relação à potência infinita e ao processo de constituição dos direitos comuns, medida do direito do Estado. Essa ideia de que o direito natural da multidão envolve um processo permanente de afirmação no real expressa uma guinada na concepção sobre a obediência política e na própria noção de contrato.

A conservação do direito natural - e do direito de resistência proposta por Spinoza assinala uma nova compreensão sobre a relação entre contrato e obediência política. O contrato, no pensamento político spinozano, não é um acordo de vontades livres que representa a transferência do direito natural, mas um índice de um consenso que a cada dia e a cada hora deve ser renovado e obtido pelo Estado perante a multidão (CHAUI, 2003, p 314). Isso porque “[...] ninguém, com efeito, pode alguma vez transferir para outrem o seu poder e, consequentemente, o seu direito, a ponto de renunciar a ser um homem" (SPINOZA, 2003, Capítulo XX). O contrato aparece apenas no Tratado Teológico-Político e, a rigor, representa uma mera imagem do processo de constituição da potência da multidão e sua institucionalização por intermédio da organização política. Antonio Negri exprime em perfeita síntese o que aqui se afirma sobre o contrato:

Primeiro ponto, portanto: crítica da ideia de transferência transcendental do direito natural, crítica da gênese jurídica do poder. É colocado o problema da diferença "súdito"-"cidadão". Dentro dos preceitos consolidados do jusnaturalismo, essa diferença é mediada e organizada pelo contrato, nas várias formas em que este é proposto, mas que em cada caso sobredeterminam o simples fenômeno associativo. Mas em Spinoza o contrato já está eliminado, assim como está eliminada sua caracterização individualista. Aqui, então, a eliminação do contrato funciona de maneira positiva. A passagem do individual ao geral é negada por Spinoza por princípio. A passagem se dá em termos coletivos. Não se trata então de transferência de direito, mas de sua constituição coletiva. (NEGRI, 1993, p. 254) 
Se a transferência integral do direito natural é impossível, confirmase a tese de que o direito de resistência persevera no interior do estado civil e é a medida do poder constituído pela multidão. É impossível ceder o direito natural porque ele é expressão da potência de perseverar da multidão e dos indivíduos. Não é porque estão em sociedade que os homens deixam de desejar, de ter apetites, de produzir juízos e de experimentar afetos. Essa dinâmica físico-afetiva da existência caracteriza todos os homens. A organização política pode, apenas e tão somente, evitar que os desejos, apetites, afetos e juízos se materializem em atos que ponham em risco as fundações da política, ou seja, a potência da multidão e seu efeito imediato, o direito da cidade. Mas é impossível exigir que os seres humanos pensem, sintam e desejem o mesmo ${ }^{5}$. Porque é física e logicamente impossível renunciar ao direito natural, Spinoza conclui ser perfeitamente factível romper o pacto firmado com os governantes. Se os governantes não conseguirem atualizar permanentemente o consenso, o pacto perderá a sua utilidade e, deste modo, poderá ser rompido. Como demonstra a passagem a seguir:

Só por malícia alguém prometerá renunciar ao direito que tem sobre todas as coisas, e que só por medo de um mal maior ou na esperança de um bem maior alguém cumprirá tais promessas. Para que isso fique mais claro, suponhamos que um ladrão me obrigue a prometer que lhe vou entregar os meus bens onde ele quiser. Uma vez que o meu direito natural está limitado, como já demonstrei, apenas pela minha potência, é evidente que, se eu puder, astuciosamente libertar-me desse ladrão prometendo-lhe tudo o que ele quiser, ser-me-á lícito, por direito natural, fazê-lo, ou seja, ludibriá-lo, aceitando o contrato que ele me propõe [...]. Conclui-se que um pacto não pode ter nenhuma força a não ser em função da sua utilidade e

\footnotetext{
5 Étienne Balibar, ao pôr o problema em perspectiva contemporânea, assinala: "Spinoza é o anti-Orwell, pois para ele é impensável uma redução ou controle absoluto do sentido das palavras, ou mesmo a redução absoluta da individualidade pela massa - ou da massa sendo absorvida pela individualidade que está no poder. Esses casos extremos, que seriam negações radicais ou figuras da morte, presentes na vida, são também ficções, eventos fisicamente impossíveis - portanto intelectualmente inúteis e politicamente nefastas". (BALIBAR, 1997, p. 98)
} 
que, desaparecida esta, imediatamente o pacto fica abolido e sem eficácia. (SPINOZA, 2003, Capítulo XVI)

Esse raciocínio aponta para um movimento constituinte constante, permanente, pois a perda da capacidade de renovação do consenso induz a uma experiência afetiva contrária à aceitação, pela multidão, de certo regime instituído ${ }^{6}$. A exigência de que os governantes renovem permanentemente o consenso no interior da multidão, visto que este não é um fundamento abstrato, mas necessariamente atual, do poder do Estado, põe em cena a questão dos limites do poder do Estado. Essa questão é apresentada por Spinoza nos seguintes termos: “[...] costuma perguntar-se, no entanto, se o poder soberano está adstrito às leis e consequentemente pode pecar" (SPINOZA, 2009, IV, 4). Sua. resposta é a seguinte: “A cidade peca quando faz ou deixa de fazer coisas que podem ser causa da sua própria ruína" (SPINOZA, 2009, IV, 4). A ruína da Cidade se dá quando ela atenta contra o direito natural da multidão, o que termina por produzir a indignação da maioria. Eis o pecado da cidade: a criação das condições de difusão generalizada do afeto de indignação. É importante analisar o trecho em que Spinoza assinala esta posição:

Pertence menos ao direito da cidade aquilo que provoca a indignação da maioria. É, com efeito, certo que os homens por inclinação da natureza conspiram, seja por causa de um medo comum, seja pelo desejo de vingar algum dano comumente sofrido. E uma vez que o direito da cidade se define pela potência comum da multidão, é certo que a potência e o direito da cidade diminuem na medida em que ela própria ofereça motivos para que vários conspirem. Há certamente coisas de que a cidade deve ter medo. (SPINOZA, 2009, III, 9)

6 Nesse mesmo sentido, Marilena Chauí afirma que “[...] a instituição do Estado não cessa de ser refeita e isso não tanto pela ação das forças exteriores e sim muito mais pelas tensões internas, pois o conatus coletivo é feito de concordâncias e conflitos, de partes fortes e fracas, de risco incessante de diminuição da liberdade e da igualdade e da confusão entre a paz e a mera ausência de guerra”. (CHAUÍ, 2003, p. 314) 
Ou seja, diante de um Estado que não procura renovar o consenso da multidão, o direito de guerra, expressão do direito de resistência, se exercerá necessariamente, na medida em que é ele que sustenta o contrato, e não o direito civil. É o que afirma Spinoza no seguinte trecho:

O contrato, ou as leis pelas quais a multidão transfere o seu direito para um só conselho ou para um só homem devem, sem dúvida, ser violadas quando interessa a salvação comum violá-las [...]. Se, contudo, elas são de natureza tal que não podem ser violadas sem que ao mesmo tempo se debilite a robustez da cidade, isto é, sem que ao mesmo tempo o medo comum da maioria dos cidadãos se converta em indignação, a cidade, por isso mesmo, dissolve-se e cessa o contrato, o qual, por conseguinte, não é defendido pelo direito civil, mas pelo direito de guerra. (SPINOZA, 2009, IV, 6)

A violação do consenso ou sua não renovação constituem causas de ruína do Estado e autorizam o exercício do direito de resistência pela multidão. Na verdade, a contínua produção da aceitação de um determinado governo é essencial para que a dinâmica afetiva seja favorável à obediência política. Na base da obediência se encontra um conjunto de afetos tendentes a ela. Assim, no momento em que cessa a disposição afetiva de obedecer e se alastra a indignação, a resistência não apenas é desejável, mas necessária ${ }^{7}$.

É importante ressaltar que a resistência assume um caráter positivo em Spinoza. Resistir não significa apenas contrariar certo estado de coisas ou uma simples ruptura de um determinado pacto, mas, sobretudo, afirmar uma potência voltada à recomposição dos fundamentos da organização política. Há situações-limite em que desobedecer aos governantes é o mesmo que obedecer aos fundamentos do Estado. Se o direito natural da multidão é o fundamento e a medida do poder do Estado, a desobe-

7 Em David Hume é possível reencontrar esta figura da resistência pela indignação: “[...] sempre que o magistrado civil leva sua opressão ao ponto de tornar sua autoridade intolerável, não temos mais obrigação de nos submeter a ele. A causa cessa; o efeito, portanto, também deve cessar" (HUME, 2001, p. 590). Em outro texto trata-se brevemente dos pontos de contato entre Spinoza e Hume, no contexto do iluminismo europeu. (ROCHA; GUIMARAENS, 2011) 
diência aos governantes pode ser considerada uma medida de salvação pública, em certos momentos em que o fundamento do direito civil, a potência da multidão, for afrontado por alguma determinação do poder instituído. A imagem de Ulisses acorrentado ao mastro do navio é usada por Spinoza para sustentar o argumento da necessidade de desobediência de atos dos governantes que venham a atingir os fundamentos do Estado. Os companheiros de Ulisses, ao desobedecerem suas ordens de desamarrá-lo do mastro, no momento em que ele se encontrava encantado pelo canto das sereias, a rigor obedeceram a ordem anterior de Ulisses de jamais desatá-lo do mastro, ainda que sob ameaça de punição futura. De acordo com Spinoza a respeito do Estado monárquico:

Os fundamentos do Estado devem ser tidos como decretos eternos do rei, de tal maneira que os seus funcionários lhe obedecerão completamente se, quando ele der alguma ordem que repugne aos fundamentos do Estado, se negarem a executar o que ele mandou. Podemos claramente explicá-lo com o exemplo de Ulisses. Foi, com efeito, uma ordem do próprio Ulisses que os companheiros deste executaram quando, atado ao mastro do navio e com a mente apanhada pelo canto das sereias, o não quiseram desatar, embora fosse isso que ele, ameaçando de muitos modos, ordenava. (SPINOZA, 2009, VII, p. 1)

Em suma, se desobedecer um governante que não considera a necessidade de contínua atualização do consenso da multidão é o mesmo que obedecer os fundamentos do Estado, que repousam no direito natural da multidão, conclui-se necessariamente que o direito de resistência sustenta o processo de constituição e de atualização do consenso da multidão.

\section{A Expressão Política e Institucional do Direito de Resistência: a liberdade de expressão e o controle popular das armas}

Após demonstrar que o direito de resistência sustenta o estado civil e se identifica com a potência da multidão, seu direito natural, é necessário investigar de que maneira esse direito se exprime politicamente. $\mathrm{O}$ direito de resistência no pensamento de Spinoza se exprime de três ma- 
neiras: pela afirmação de limites cognitivos, afetivos e físicos ao poder do Estado, pela institucionalização de mecanismos democráticos de orientação das decisões dos governantes e pela expressão da potência constitutiva da multidão.

Os limites cognitivos ao exercício do poder do Estado se encontram com nitidez no capítulo XX do Tratado Teológico-Político, que trata da liberdade de expressão. Este capítulo apresenta duas teses fundamentais sobre a liberdade de expressão. A primeira tese aponta para a impossibilidade de limitação absoluta da liberdade de pensamento e de sua manifestação. A segunda indica que a restrição da liberdade de pensamento pode levar o Estado à ruína por estimular os vícios, e não as virtudes.

Para Spinoza, é impossível que os indivíduos transfiram para o Estado sua potência de pensar. Na medida em que cada indivíduo possui um corpo singular e uma mente igualmente singular, forma juízos e ideias singulares, sobretudo aquelas relativas ao primeiro gênero de conhecimento. A expressão singular da potência de pensar das mentes dos indivíduos é necessária. Por mais que estejam submetidos ao domínio do poder do Estado, inevitavelmente a singularidade cognitiva dos indivíduos contrariará, em algum momento, os desígnios do poder instituído, pois nem todas as determinações estarão de acordo com os desejos e, portanto, com os juízos de cada um. Como se lê a seguir:

Por maior que seja, pois, o direito que têm os supremos poderes sobre todas as coisas, e por muito que os consideremos como intérpretes do direito e da piedade, eles jamais poderão evitar que os homens façam sobre as coisas um juízo que depende de sua própria maneira de ser ou que estejam possuídos desta ou daquela paixão [...]. Portanto, se ninguém pode renunciar à sua liberdade de julgar e pensar o que quiser, e se cada um é senhor dos seus próprios pensamentos por superior direito de natureza, jamais será possível, numa comunidade política, tentar, sem resultados funestos, que os homens, apesar de terem opiniões diferentes e até opostas, não digam nada que não esteja de acordo com aquilo que prescrevem as autoridades. (SPINOZA, 2003, Capítulo XX) 
Se não há transferência integral do direito de emitir juízos próprios, percebe-se que a tentativa de limitação deste direito atinge o direito natural dos indivíduos e da multidão por eles constituída, o que significa risco para a própria existência do Estado e autoriza a desobediência de prescrições que busquem limitar essa liberdade. Além disso, Spinoza entende que a restrição à liberdade de expressão do pensamento só é nociva aos homens livres, que manifestam verdadeiramente sua opinião. Os aduladores, os conspiradores e os mentirosos são os que mais se beneficiam das prescrições contra tal liberdade. Em suma, o Estado que opta por se opor à mesma dá um grande passo para a destruição de seus fundamentos, pois, de um só golpe, viola a necessária expressão cognitiva do esforço em perseverar na existência dos cidadãos e cria as condições para proliferação da adulação, da conspiração e da mentira, causas de destruição das instituições políticas. A diversidade dos juízos é, sobretudo, um dado da natureza dos indivíduos, razão pela qual um regime que busque limitar essa diversidade pela proibição da liberdade de expressão é intolerável e causa de indignação da multidão.

Mas a pergunta a ser feita é a seguinte: em que medida a liberdade de expressão do pensamento pode ser considerada uma forma de expressão do direito de resistência, um limite cognitivo ao exercício do poder do Estado? Duas são as evidências. Em primeiro lugar, a liberdade de expressão do pensamento, por não ser jamais completamente transferida para o Estado, é parte do direito natural da multidão. Por essa razão, qualquer tentativa de supressão da mesma enseja a resistência daqueles que possuem essa liberdade. Em segundo lugar, a afirmação da liberdade de expressão é o pressuposto para o combate de opiniões que visem instituir a tirania em certo estado civil. A diversidade de opiniões é essencial para limitar as ideias cuja finalidade seja a transferência dos direitos da multidão além da medida necessária, afinal as ideias se limitam reciprocamente.

Apenas uma ideia pode limitar outra ideia é o que afirma Spinoza na Definição 2 da Parte I da Ética. O combate contra ideias que visem a lançar o canto das sereias sobre a multidão não pode ser feito à moda de Ulisses, visto que é impossível atar a multidão ao mastro. A contenção da multidão pressupõe uma autocontenção, que só se realiza pela diversidade de opiniões. As ideias contrárias à garantia da paz e da liberdade só 
podem ser limitadas por outras, contrárias e mais fortes, que demonstrem à multidão o risco contido nas primeiras ideias. A liberdade de expressão do pensamento, deste modo, é útil e necessária estratégia de resistência à tirania, pois é o enfrentamento ideológico que permite repelir os desejos tirânicos e as ideias que os expressam. (BOVE, 1996, p. 272)

Os limites ao poder instituído não se revelam apenas nos embates de ideias que a liberdade de expressão estimula. A tirania não é repelida somente mediante mecanismos cognitivos. Há outro exemplo de limite do poder do Estado cuja natureza envolve uma dimensão física e afetiva. Para entender adequadamente esta questão, é necessário enfrentar um trecho do Tratado Político no qual ela é posta:

Com que recompensas ou ameaças pode o homem ser induzido a amar quem ele odeia, ou a odiar quem ele ama? E, aqui, há também que referir aquelas coisas que a natureza humana abomina a tal ponto que as tem por piores que qualquer mal, seja, o homem testemunhar contra si mesmo, torturar-se, matar os seus pais, não se esforçar por evitar a morte e coisas semelhantes a que ninguém pode ser induzido, nem com recompensas, nem com ameaças. (SPINOZA, 2009, III, p. 8)

De início, é preciso esclarecer que Spinoza não entende os limites mencionados no Tratado Político a partir de uma perspectiva moral ou mesmo de uma ordem anterior ao Estado que deve ser obedecida. A impossibilidade de que alguém seja obrigado a causar um mal a si mesmo ou a entes queridos decorre do modo de organização do corpo e da mente do homem. Torturar-se e não se esforçar por evitar a morte são ações inconcebíveis em razão pura e simplesmente do esforço em perseverar na existência afirmado pelo corpo humano. Todo e qualquer corpo se esforça por evitar a dor e qualquer padecimento tendente à sua decomposição. Este exemplo traduz fielmente a afirmação feita no Tratado Teológico Político segundo a qual é impossível transferir integralmente o direito natural, ou seja, a potência própria de perseverança na existência. O conatus corporal é um limite físico intransponível ao poder instituído. 
O mesmo raciocínio se aplica às demais ações citadas na passagem acima. Testemunhar contra si mesmo e matar os próprios pais são atos que provocariam, no primeiro caso, tamanho temor da punição e, no segundo caso, tão profundas culpa e tristeza que em nenhuma hipótese poderiam ser praticados. Existe, nestes casos e em outros semelhantes, um evidente limite afetivo, pois não se suporta ser causa de nossa própria tristeza ou da tristeza daqueles a quem se ama. Nesta última hipótese, inclusive, a tristeza ocorre em dobro, na medida em que aquele que causa um mal a entes queridos se entristece por vê-los padecer e por ser a causa desse padecimento. Por tais razões físicas e afetivas, a resistência nestes casos não apenas é desejável, mas é, sobretudo, necessária.

A outra forma de expressão do direito de resistência se dá pela institucionalização de mecanismos de constituição do consenso no interior do estado civil. A instituição apontada por Spinoza como a mais útil para atingir tal finalidade em um Estado monárquico se inspira no pensamento maquiaveliano. O "povo em armas", como sugere Spinoza, representa instituição essencial para a garantia da paz e da constituição do consenso. O raciocínio spinozano é desenvolvido quando da análise da melhor forma de se organizar uma monarquia. Segundo Spinoza:

Um rei está tanto menos sob jurisdição de si próprio, e a condição dos súditos é tanto mais miserável, quanto mais o direito da cidade se transfere absolutamente para ele. Assim, para estabelecer corretamente um estado monárquico, é necessário lançar fundamentos firmes, sobre os quais ele seja edificado e dos quais resulte a segurança do monarca e a paz da multidão, de tal modo que o monarca esteja tanto mais sob jurisdição de si próprio quanto mais atender à salvação da multidão. (SPINOZA, 2009, VI, p. 8)

A questão que se apresenta é a seguinte: como convencer um rei, ou qualquer governante, a se orientar por este enunciado? Como confiar no bom senso dos governantes? Spinoza, em inúmeros momentos de sua obra, recusa depositar a liberdade na boa vontade dos homens. Conforme expresso no Tratado Político: "[...] um Estado cuja salvação depende da lealdade de alguém e cujos assuntos só podem ser corretamente geridos se aqueles que deles tratam quiserem agir lealmente, não terá a míni- 
ma estabilidade" (SPINOZA, 2009, I, 6). Trata-se, portanto, de instituir dispositivos impessoais e institucionais que levem os governantes a agir conforme ao direito natural da multidão. A aposta de Spinoza não se dirige a qualquer virtude privada, mas sim à organização institucional capaz de levar os governantes, seja por sua boa índole, seja por medo, seja por desejo de glória ou outro afeto qualquer, a governar de acordo com a vontade da multidão. É o que se deduz da passagem a seguir: "Nem importa, para a segurança do Estado, com que ânimo os homens são induzidos a administrar corretamente as coisas, contanto que as coisas sejam corretamente administradas". (SPINOZA, 2009, I, p. 6)

Volta-se à pergunta inicial: como levar um monarca a consultar e a sufragar as opiniões da multidão? A alternativa institucional, para Spinoza, é manter as armas sob o controle dos cidadãos. Com isso o pensador holandês antecipa uma tese constitucional consagrada: a da subordinação das forças militares ao poder civil e aos procedimentos democráticos. Esta tese tem duas funções: evitar a instituição de corporações militares que afirmem seus próprios interesses contra os do Estado e se constituam em um "[...] império dentro de um império [...]"; e produzir no monarca o afeto do medo da multidão, necessário para que ela seja habitualmente consultada pelo monarca e que as decisões políticas não sejam assunto exclusivo de gabinetes oligárquicos.

A democratização do controle sobre as armas é o contra poder necessário à garantia do direito natural da multidão perante ameaças do monarca. Os reis devem temer permanentemente a multidão, para que sejam forçados a desenvolver o hábito de consultá-la ao decidir. A multidão armada levará os governantes a sempre considerar sua opinião e somente deste modo se produzirá no governante permanentemente um afeto contrário e mais forte ao desejo de escravizar a multidão. Os governantes que não temem podem ser seduzidos pelos cantos de seus próprios desejos, ou mesmo de desejos de maus conselheiros. Desse modo, é útil que os governantes tenham razões constantes para temer a multidão, refreando as paixões tirânicas que eventualmente venham a experimentar. A passagem a seguir ilustra bem esse raciocínio: 
Seja, portanto, conduzido pelo medo da multidão, seja para pôr do seu lado a maioria da multidão armada, seja conduzido pela generosidade de ânimo, para atender ao interesse público, o rei subscreverá sempre a opinião que tiver mais votos, isto é, aquela que for mais útil à maior parte do estado. Ou então procurará conciliar, se possível, as opiniões discrepantes que lhe foram deferidas, a fim de atrair todos a si, coisa em que porá todo o seu vigor, e para que eles experimentem, na paz como na guerra, o que só nele próprio têm. Desse modo, estará maximamente sob jurisdição de si próprio e terá maximamente o estado quando atender maximamente à salvação comum da multidão. (SPINOZA, 2009, VII, p. 11)

Ou seja, ao perceber que a multidão tem condições efetivas de resistir pelo manejo das armas que estão sob seu domínio, qualquer governante será conduzido a consultá-la ao decidir. O direito de resistência, mais uma vez, é a medida adequada à garantia da paz e da liberdade, a ponto de se manifestar institucionalmente mediante a democratização do controle do uso das armas. É preciso registrar que o direito de resistência, neste caso, é concebido não como um direito de ruptura do pacto, ou seja, como um direito externo ao pacto, mas sim como um direito que o sustenta. A instituição do "povo em armas", já proposta um século e meio antes de Spinoza por Maquiavel, constitui uma espécie de institucionalização do direito de resistência. Não se trata de um direito de ruptura e reorganização políticas, qual o direito de romper o pacto, e sim de um mecanismo de consulta contínua à multidão pelos governantes e de afirmação permanente da causa do direito do Estado, a potência da multidão.

A institucionalização da resistência tem por objetivo evitar a situação-limite em que a ruptura institucional e política torna-se inevitável, pois essa ruptura se abre violentamente à contingência e seus efeitos são invariavelmente imprevisíveis. Por isso, para Spinoza, a melhor alternativa é constituir mecanismos institucionais capazes de conservar e de atualizar permanentemente o princípio da política, a potência da multidão, a fim de evitar o exercício dessa potência mediante o direito de guerra. Ao fim e ao cabo, a internalização do direito de resistência é condição necessária para conservar a liberdade. 


\section{Conclusão}

O direito de resistência concebido a partir de Spinoza assume outra feição, anômala e original. Na verdade, o direito de resistência perde seu caráter episódico e deixa de ser uma mera ameaça latente que paira sobre os governantes e que se relaciona com o tempo passado e pactuado. $\mathrm{Na}$ verdade, a própria teoria da potência de Spinoza se exprime com nitidez em seu pensamento político quando se trata da questão da resistência.

A resistência pensada a partir de Spinoza é atual, e não potencial. O tempo da resistência é o presente. Spinoza trata de uma resistência que se renova continuamente e, portanto, é o próprio fundamento da soberania. A resistência se afirma necessariamente, seja porque os homens por natureza desejam governar e não ser governados, seja porque o princípio da singularidade desenvolvido em sua filosofia exige a necessária diversidade de juízos e divergência de opiniões. Contrariar continuamente o desejo de governar e de não ser governado ou forçar os homens a ter outras opiniões pode conduzir à indignação da maioria e levar o governante à sua própria ruína. A liberdade de expressão e o controle democrático das armas têm a função de institucionalizar a resistência, torná-la habitual, e não excepcional, o que é essencial para evitar a indignação da maioria dos cidadãos.

Mas a resistência em Spinoza é também tempo futuro, possibilidade de ruptura dos pactos, seguida da instituição de novos e distintos pactos, mesmo na hipótese de seu fiel cumprimento. Eis mais uma originalidade de Spinoza: se o desejo é variável e se o desejo, ele mesmo, funda e sustenta os pactos, a variação do desejo da multidão pode causar a refundação do pacto, ainda que os governantes o cumpram. Uma resistência, outro tempo, outra concepção de direito: pelo direito de resistência é possível compreender elementos fundamentais da inovação spinozana para o pensamento político-jurídico. Essa é sua relevância para a filosofia spinozana. 


\section{Referências}

BALIBAR, Étienne. Spinoza et la politique. Paris: PUF, 1990. . Spinoza, l'anti Orwell in La crainte des masses. Paris:

Galilée, 1997.

BOBBIO, Norberto. Locke e o direito natural. 3. ed. Brasília: DF, UnB, 1997.

Estado, governo, sociedade: para uma teoria geral da política. São Paulo: Paz e Terra, 2003.

. A resistência à opressão, hoje. In: A era dos direitos. 10. ed. Rio de Janeiro: Elsevier, 2004.

LA BOÉTIE, Étienne. Discurso da servidão voluntária. São Paulo: Brasiliense, 1987.

BOVE, Laurent. La stratégie du conatus: affirmation et résistance chez Spinoza. Paris: Vrin, 1996.

. Espinosa e a psicologia social. São Paulo; Belo Horizonte: Nupsi-USP; Autêntica, 2010.

. Direito de Guerra e Direito Comum na Política Spinozista. Revista Conatus, [on-line], v. 2, n. 4, 2008. Disponível em; < http:// www.benedictusdespinoza.pro.br/index.html > . Acesso em: 25 nov. 2014. BOVE, Laurent; MOREAU, Pierre-François. Le Traité Politique, une radicalisation conceptuelle? In: JAQUET, Chantal; SÉVÉRAC, Pascal; SUHAMY, Ariel. (Org.) La multitude libre. Paris: Éditions Amsterdam, 2009. p. 27-44.

CAMPOS, André Santos. Jus sive potentia, Direito natural e individuação em Spinoza. Lisboa: Centro de Filosofia da Universidade de Lisboa, 2010.

CARVALHO, Frank Viana de. O pensamento político monarcômaco. Tese de Doutoramento: FFLCH USP, 2007.

CHAUI, Marilena. Política em Spinoza. São Paulo: Companhia das Letras, 2003. 
. Da realidade sem mistérios ao mistério do mundo. São Paulo:

Brasiliense, 1999.

GOYARD-FABRE, S. Os fundamentos da ordem jurídica. São Paulo:

Martins Fontes, 2002.

HUME, David. Tratado da Natureza Humana. São Paulo: Unesp;

Imprensa Oficial do Estado de São Paulo, 2001.

LA BOÉTIE, Étienne de. Discurso sobre a servidão voluntária. São

Paulo: Revista dos Tribunais, 2003.

MAQUIAVEL, Nicolau. Discurso sobre a primeira década de Tito Lívio. São Paulo: Martins Fontes, 2007.

MATHERON, Alexandre. Spinoza et la problématique juridique de Grotius. In: Études sur Spinoza et les philosophies de l'âge classique. Paris: ENS Éditions, 2011.

NEGRI, Antonio. A anomalia selvagem: poder e potência em Spinoza. Rio de Janeiro: Editora 34, 1993.

REALE, Miguel. Filosofia do direito. 18. ed. São Paulo: Saraiva, 1998.

ROCHA, M.; GUIMARAENS, F. Spinoza, as Luzes Radicais e o fim do finalismo: considerações sobre os impactos éticos e jurídico-políticos da filosofia spinozana. In: RIBEIRO FERREIRA, M. L.; AURÉLIO, D. P.; FERON, O. (Org.). Spinoza Ser e Agir. Lisboa: Centro de Filosofia da Universidade de Lisboa, 2011.

ROQUE, Tatiana. Resistir a quê? Ou melhor, resistir o quê? Revista Lugar Comum: Estudos de Mídia, Cultura e Democracia, Rio de Janeiro, v. 17, setembro-abril, 2002.

SKINNER, Quentin. Fundações do pensamento político moderno. São Paulo: Companhia das Letras, 1996.

SPINOZA. Traité Politique. Texto em latim estabelecido por Omero Proietti. Tradução, apresentação, notas, glossário, index e bibliografia por Charles Ramond. Prefácio de Pierre-François Moreau e notas de Alexandre Matheron. PUF, 2005. 
. Tratado Político. Tradução, introdução e notas por Diogo Pires Aurélio; revisão da tradução por Homero Santiago. São Paulo: WMF Martins Fontes, 2009.

. Traité Téologique-Politique. Texto em latim estabelecido por Fokke Akkerman, trad. e notas por Jacqueline Lagrée e P. F. Moreau. PUF, 1999.

. Tratado Teológico-Político. Tradução, introdução e notas por Diogo Pires Aurélio. São Paulo: Martins Fontes, 2003.

. Ética. Tradução e notas de Tomaz Tadeu. Ed. bilíngüe Latim/ Português. B. Horizonte: Autêntica, 2007.

. Carta L. Tradução e notas de M. Chauí. Volume Baruch de Espinosa da coleção Os Pensadores. São Paulo, 1973.

ZOURABICHVILI, François. L'énigme de la multitude libre. In: JAQUET, Chantal; SÉVÉRAC, Pascal; SUHAMY, Ariel. (Org.). La multitude libre. Paris: Éditions Amsterdam, 2009.

Francisco de Guimaraens é Professor do Programa de Pós-Graduação em Direito do Departamento de Direito da Pontifícia Universidade Católica do Rio de Janeiro. Doutor em Direito pela PUC-Rio.

E-mail: chicodeguima@gmail.com; chicodeguima@puc-rio.br

Endereço profissional: Pontíficia Universidade Católica do Rio de Janeiro, Rua Marquês de São Vicente, 225, Gávea, RJ, Brasil.

Maurício Rocha é Professor do Programa de Pós-Graduação em Direito do Departamento de Direito da Pontifícia Universidade Católica do Rio de Janeiro. Doutor em Filosofia pela PUC-Rio.

E-mail: cawaipe@gmail.com

Endereço profissional: Pontíficia Universidade Católica do Rio de Janeiro, Rua Marquês de São Vicente, 225, Gávea, RJ, Brasil. 
